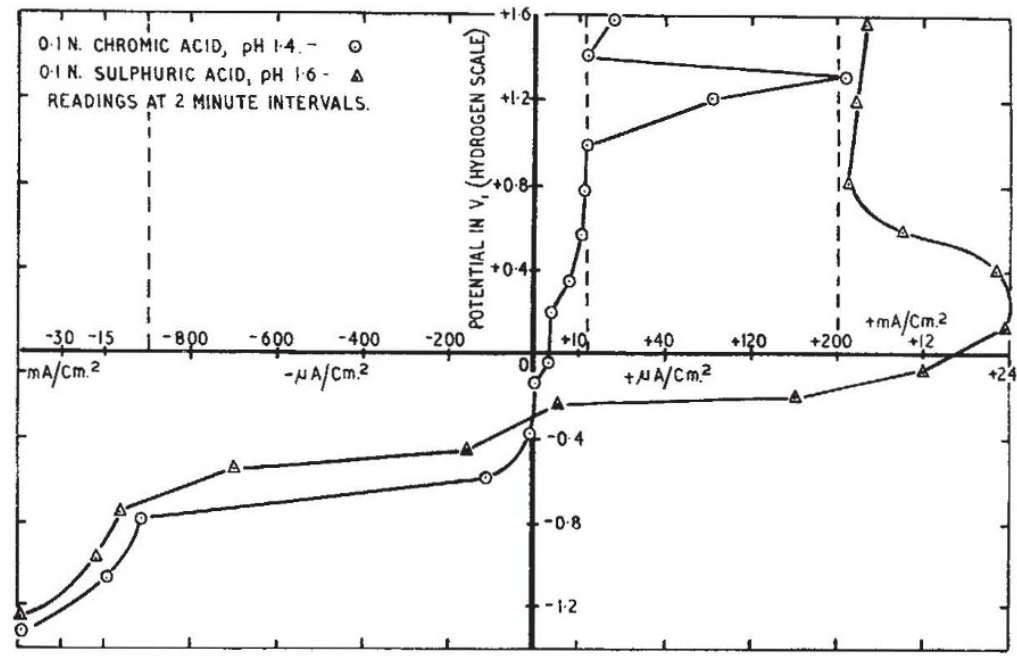

Fig. 1

was applied across the electrodes. Increased protective power of the film, probably corresponding to oxidation of ferrous to ferric oxide, was achieved at $+0.8 \mathrm{~V}$. Results obtained in chromic acid showed a protective film formed. at $-0.4 \mathrm{~V}$, a potential corresponding to ferrous ion formation, while the anodic current density necessary to maintain iron at $+0.4 \mathrm{~V}$, the potential corresponding to that of inhibited iron at $p H \quad 1 \cdot 6$, is $10 \mu a m p / \mathrm{cm}^{2}$ in chromic acid, and $24 \mathrm{~m} \cdot \mathrm{amp} / \mathrm{cm}^{2}$ in sulphuric acid. The protective power of the film formed in chromic acid broke down at $+1.2 \mathrm{~V}$, the potential corresponding to oxidation of chromic ion to chromate.

Previous work has shown ${ }^{2}$ that the cathodic exchange current on iron produced by chromate is very small, and chromate does not owe its powors of inhibition to polarization of iron to a passive potential. Chromate is held exchangeably in amounts approaching a monolayer on passive iron ${ }^{3}$.

It is concluded that the functions of chromate and its reduction products in inhibiting corrosion of iron are to slow down the rate of solution of the air-formed oxide film and/or to form a protective film on oxide-free surfaces.

The rate of solution of the air-formed oxide may be lowered by the irreversible absorption of chromic ions into the oxide film to form a mixed iron-chromic oxide, with reversible adsorption of chromate at the oxide solution interface. The protective film formed at the oxide-free surface at the potential corresponding to ferrous ion formation may be a mixed ferrous chromic oxide with adsorbed chromato; it is not ferrous oxide, which is soluble at this $p H$, while results from the potentiostat indicate that chromic ion is essential for the stability of this film.

Australian Defence Scientific Service,

Aeronautical Research Laboratory, Melbourno.

'Hancock, P., and Mayne, J. E. O., J. Chem. Soc., 4167 (1958).

${ }^{2}$ Cartledge, G. H., Corrosion, 18, 316 (1962).

${ }^{3}$ Cartledge, G. H., and Spahrbier, D. H., J. Electrochem. Soc., 110, 664 (1963).

\section{Determination of Nitric Oxide}

THe methods available for the quantitative determination of nitric oxide in the absence of air involve differential manometric techniques, ${ }^{1,2}$. This communication describes a direct method for the quantitative determination of the gas. The procedure consists of the oxidation of nitric oxide to nitrite by alkaline permanganate solution. Nitrite is quantitatively recovered after adding alkalino arsenite solution to precipitate the permanganate as insoluble manganese dioxide.

Nitric oxide was produced by reducing nitrite with an excess of acidified iodide according to the mothod of Johnston and Giauquo $^{3}$. Since small amounts of nitrous oxide were also formed, nitrogen balanes experiments were made in Warburg respirometers. Double side-arm flasks having a capacity of $16 \mathrm{ml}$. were used. The main compartment contained a solution of 0.5 m-equivalent of sulphuric acid and 0.25 m.mole of potassium iodide in $2.3 \mathrm{ml}$. of water. One side-arm held a solution of $25-100 \mu$ moles of sodium nitrito in $0.2 \mathrm{ml}$. of water. The other side-arm contained $0.4 \mathrm{ml}$. of a solution of $200 \mathrm{mM}$ potassium permanganate in $2 \mathrm{~N}$ sodium hydroxide. The flasks were gassed for $20 \mathrm{~min}$ with nitrogen which contained only 0.02 per cent oxygen (obtained from Air Products, Ltd.). After temperature equilibration at $30^{\circ} \mathrm{C}$, the manometers were removed from the water bath and the nitrite was added from the side-arm.

The formation of nitric oxide, which was complete in 5 min, was great and it was found necessary to hold down the stoppers of the flask by hand. The vessels were rocked slowly for $10 \mathrm{~min}$ to agitate the permanganate and thus increase the rate of absorption of the gas. The vessels were again placed in the water bath and shaken at 80 strokes/min. After a further $40 \mathrm{~min}$, stationary readings, representing small amounts of nitrous oxide, were obtained.

The alkaline permanganate reagent was removed from the side-arm and $0 \cdot 2-\mathrm{ml}$. samples were added to a solution of $2 \mathrm{ml}$. of 2 per cent sodium arsenite and $2.8 \mathrm{ml}$. of $2 \mathrm{~N}$ sodium hydroxide. The precipitate of manganese dioxide so formed was allowed to aggregate for $10 \mathrm{~min}$. The mixture was then centrifuged at $2,000 \mathrm{~g}$ for $3 \mathrm{~min}$. Nitrite was determined by the method of Anderson ${ }^{4}$ in suitably diluted samples of the clear supernatant.

Table 1. Relation Between the Nitrite Nitrogen Added and the RECOVERY OF NITRITE FROM THE ALKAIINE PERMaNGanate plus the RECOVRRY OF NITROUS OXIDE NITROGE

Nitrite Recovery of inorganic nitrogen compounds ( $\mu$ atoms of nitrogen) added Nitrite from the Nitrous oxide Nitric oxide plus nitrou ( $\mu$ moles) alkaline permanganatc

$\begin{array}{rrrr}25 & 24 \cdot 0 & 1 \cdot 6 & 102 \\ 50 & 46 \cdot 7 & 3 \cdot 3 & 100 \\ 75 & 75 \cdot 0 & 3 \cdot 0 & 104 \\ 100 & 103 \cdot 5 & 0 \cdot 7 & 104\end{array}$

The results recorded in Table 1 show that the recovery of nitrite from the alkaline permanganate plus the recovery of the nitrous oxide nitrogen was equal to the nitrite nitrogen used to generate the gases. These findings show that the alkaline permanganate quantitatively oxidizes nitric oxide to nitrite.

With respect to the accuracy of the nitrogen balance and the speed of the determination, this method may prove useful for the analysis of gas mixtures containing nitric oxide. Further details of the rapid absorption of nitric oxide and a method for the determination of amounts smaller than 25 umoles will be published elsewhere.

\section{J. H. ANderson*}

Long Ashton Rosearch Station, Univorsity of Bristol.

* Present address: Department of Physiology, lniversity of Bristol.

${ }^{1}$ Chung, C. W., and Najjar, V. A., J. Biol. Chem., 218, 617 (1956).

${ }^{2}$ Anderson, J. H., Biochem. J., 91, 8 (1964).

${ }^{3}$ Johnston, H. L., and Giauque, W. F., J. Amer. Chem. Soc., 51, 3194 (1929).

4 Anderson, J. H., Analyst, 88, 494 (1963). 